\title{
RESEARCH ON DYNAMIC SCHEDULING OF SUPPLY INVENTORY DISTRIBUTION IN UNCERTAIN ENVIRONMENT
}

\author{
Xiaojuan Yuan ${ }^{*}, 12$, Chunsheng Shi ${ }^{3}$ \\ ${ }^{1}$ Harbin Institute of Technology, Harbin, Heilongjiang Province, 150001, China \\ ${ }^{2}$ Guilin Tourism University, Guilin, Guangxi Province, 541006, China \\ ${ }^{3}$ School of Management Harbin Institute of Technology, Harbin, Heilongjiang Province, 150001, China \\ Correspondence address: No. 3, Fuxing Road, Qixing District, Guilin City, Guangxi Zhuang Autonomous Region, \\ Guangxi Province, 541004, China \\ *E-mail: xiaojuanyhit@yeah.net
}

\begin{abstract}
With the development of China's economy, various manufacturers have formed a supply inventory distribution network to meet more customer demands and improve production efficiency, and the dynamic scheduling of the network is particularly important. However, there are various uncertainties that can affect the stability of operation in the distribution network. In this study, in order to solve the dynamic scheduling problem in uncertain environment, the optimal solution of dynamic scheduling of supply inventory in uncertain environment was calculated based on the adaptive genetic algorithm, the validity of the genetic algorithm and adaptive genetic algorithm was compared and verified by numerical simulation experiment on Matlab, and the influencing factors of cost were analyzed. The results showed that: (1) the adaptive genetic algorithm was more efficient than genetic algorithm in solving the optimal solution of dynamic scheduling; (2) the cost of dynamic scheduling tended to decrease first and then increase with the increase of the maximum lead time of the manufacturers.
\end{abstract}

Keywords: Inventory Distribution, the Adaptive Genetic Algorithm, Dynamic Scheduling, Uncertain Environment.

\section{Introduction}

With the continuous development of economy, the market competition centering on customer demand becomes more and more intense. Enterprises need to reduce production time, reduce costs and improve the speed of feedback to the demands of users according to their own situations [4]. Therefore, the supply inventory distribution system came into being. The system is essentially a cooperative relationship between various suppliers and different enterprises. Thus, in order to maintain a stable and efficient system under this complex network, enterprises need to deeply understand partners, improve production quality and reduce production costs under the premise of understanding their own operation situation. In order to achieve the above objectives, dynamic scheduling, one of the management modes, was proposed and applied to deal with uncertainties in the system. Related reseaches are as follows. Li et al. [1] proposed the Hadoop logistics inventory dynamic load balance scheduling algorithm based on heartbeat feedback.

The validity of this algorithm was verified through comparing the simulation experiments under two cloud computing environments of homogeneous cluster and heterogeneous cluster. Cheng et al. [2] designed an improved ant colony optimization to minimize total cost for production, inventory and distribution. The candidate list was generated by classification of jobs to reduce the running time. In order to avoid local optimum, the pheromone was updated with a rotation scheme.

The performance of the algorithm was tested by experiments of 48 levels of instances, and the results showed the effectiveness of the proposed algorithm. Liu et al. [3] simplified the dynamic fuzzy flexible job-shop scheduling problem into a traditional static fuzzy flexible job-shop problem by adopting a series of transforming procedures. The distribution estimation algorithm was applied to solve problems, which provided an efficient and practical way to tackle the dynamic fuzzy flexible job-shop scheduling problem.

In this study, the adaptive genetic algorithm was used to calculate the optimal solution of dynamic scheduling of supply inventory distribution in uncertain environment, and the validity of the genetic algorithm and adaptive genetic algorithm was compared and verified by numerical simulation experiment on Matlab, and the influencing factors of cost were analyzed. 


\section{Supply Inventory Distribution}

As shown in Figure 1, the entire supply inventory distribution model consists of four parts: supplier, manufacturer, wholesale market and customer [5].

The produce required raw materials was provided by the suppliers, which are random normal distribution. Each supplier is independent from others. The wholesale markets inspect the inventory or place orders with the manufacturers according to the order requirements of customers; the manufacturers check the finished product warehouse after receiving orders, or purchase the raw materials from the suppliers.

The circulation of each order information between the four parts is independent and uncertain, in which case the dynamic scheduling of inventory distribution is optimized.

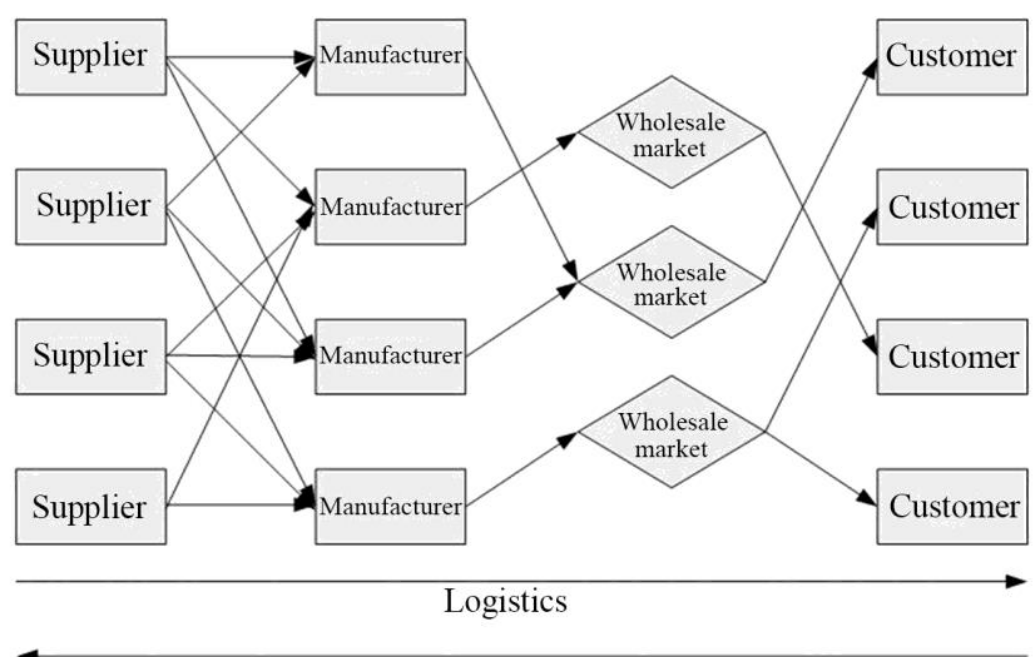

Information

Figure 1: Supply inventory distribution model

As shown in Figure 1, the entire supply inventory distribution model consists of four parts: supplier, manufacturer, wholesale market and customer [5]. The produce required raw materials was provided by the suppliers, which are random normal distribution. Each supplier is independent from others. The wholesale markets inspect the inventory or place orders with the manufacturers according to the order requirements of customers; the manufacturers check the finished product warehouse after receiving orders, or purchase the raw materials from the suppliers. The circulation of each order information between the four parts is independent and uncertain, in which case the dynamic scheduling of inventory distribution is optimized.

As the mathematical model of the entire dynamic scheduling of supply inventory distribution is relatively complex, limited by the space, only the mathematical model of the manufacturer [6] is specified:

objective: $\min : \sum_{i \in L} a_{i m_{i}}$,

condition: $\sum_{p \in J_{i j}} h_{i j p}=1 \quad \forall i \in L, j \in M_{i}$,

$a_{i 1} \geq \sum_{p \in J_{i 1}} h_{i 1 p} v_{i p} \quad \forall i \in L$,

$$
\begin{aligned}
& a_{i j} \geq \sum_{p \in J_{i j}} h_{i 1 p}\left(v_{i p}+\sigma_{i p}\right)+a_{i j-1} \quad \forall i \in L, j \in M_{i}, j \neq 1, \\
& a_{i j} \leq a i^{\prime} j^{\prime}-v_{i} p+K\left(1-g i i^{\prime} j j^{\prime} p\right)+K\left(2-h_{i j p}-h_{i^{\prime} j^{\prime} p}\right) \quad \forall i, i^{\prime} \in L, p \in J_{i j} \cap J_{i^{\prime} j^{\prime}}, \\
& a_{i^{\prime} j^{\prime}} \leq a_{i j}-v_{i p}+K g_{i i^{\prime} j j^{\prime} p}+K\left(2-h_{i j p}-h_{i^{\prime} j^{\prime} p}\right) \quad \forall i, i^{\prime} \in L, p \in J_{i j} \cap J_{i^{\prime} j^{\prime}}, \\
& h_{i j p}+h_{i^{\prime} j^{\prime} p} \leq 1 \quad \forall i \in L, j \in M_{i}, t_{i}(p, q)=0, \\
& h_{i j p}, g_{i i^{\prime} j j^{\prime} p} \in\left\{\begin{array}{ll}
0,1 & 1
\end{array}, a_{i j} \in Z^{+},\right.
\end{aligned}
$$

where $\sum_{i \in L} a_{i m_{i}}$ stands for the total production cost and time, L stands for the set of all orders, Mi stands for the set of all stages of the i-th order, $\mathrm{j}_{\mathrm{ij}}$ stands for the all possible manufacturers of the i-th order in the stage $\mathrm{j}, t_{i}(p, q)$ stands for the elements of p-row and q-column in processing matrix of the i-th order, $\sigma_{i j}$ stands for the adjustment time of the i-th order from the previous stage to the j-th stage, $v_{i p}$ stands for the processing time required for the i-th order at the $\mathrm{p}$ manufacturer, and $\mathrm{h}_{\mathrm{ijp}}$ stands for a $0-1$ variable, it occupies resource will be recorded as 1 , otherwise, it will be recorded as $0 . \mathrm{a}_{\mathrm{ij}}$ stands for the time required for $\mathrm{j}$ processing stage, and $\mathrm{x}_{\mathrm{i} \mathrm{i}^{\prime} \mathrm{j}^{\prime} \mathrm{p}} \mathrm{p}$ stands for the resources of $\mathrm{p}$ manufacturer that are shared between the $\mathrm{i}$-th order in the $\mathrm{j}$ processing stage and 
the i'-th order in the j' processing stage. If the order is completed earlier, it will be recorded as 1 , otherwise, it will be 0 .

The efficiency of solving the whole inventory distribution scheduling problem is not only related to the established mathematical model, but also related to the selected algorithm. The appropriate algorithm can solve the problem faster. In this study, adaptive genetic algorithm and genetic algorithm were chosen as the solution algorithm of the model.

\section{Adaptive Genetic Algorithm}

Genetic improvement algorithm is generally divided into chromosome coding, initial population generation, fitness value evaluation and population evolution strategy [8]. Chromosome coding mainly refers to the way that the smallest encoding character is used to reasonably represent the problem in the process of transforming data into genotype in genetic space, generally including binary encoding, integer encoding, etc. [9].

In the generation of initial population, the initial population is generally composed of several randomly generated chromosomes, which are considered to be iterative by the initial solution of the genetic algorithm. In the evaluation of fitness value, each fitness function corresponds to the quality of each chromosome, and the calculation of fitness value is also divided into decoding chromosomes, calculating the objective function value and transforming fitness [10]. Population evolution strategy is divided into selection, crossover and mutation. In traditional genetic algorithm [14], when the optimal solution is calculated, the initial chromosomes used for calculation are randomly generated, which leads to the slow convergence speed in calculation. The adaptive genetic algorithm in this study adaptively adjusted the crossover rate and mutation rate of individuals to make the initial population closer to the optimal solution. The improved adaptive crossover rate [11] and mutation rate [7] are:

$$
\begin{gathered}
\alpha= \begin{cases}\frac{n_{1}\left(G_{a v g}-G^{\prime}\right)+n_{2}\left(G^{\prime}-G_{\min }\right)}{G_{a v g}-G_{\min }} & G^{\prime}<G_{a v g} \\
\frac{n_{2}\left(G_{\max }-G^{\prime}\right)+n_{3}\left(G^{\prime}-G_{a v g}\right)}{G_{\max }-G_{a v g}} & G^{\prime} \geq G_{a v g}\end{cases} \\
\beta= \begin{cases}\frac{n_{4}\left(G_{a v g}-G^{\prime}\right)+n_{5}\left(G^{\prime}-G_{\min }\right)}{G_{a v g}-G_{\min }} & G^{\prime}<G_{a v g} \\
\frac{n_{5}\left(G_{\max }-G^{\prime}\right)+n_{6}\left(G^{\prime}-G_{a v g}\right)}{G_{\max }-G_{a v g}} & G^{\prime} \geq G_{a v g}\end{cases}
\end{gathered}
$$

where $\alpha$ stands for the crossover rate, $\beta$ stands for the mutation rate, $G$ stands for the fitness function value of chromosome, $G_{\min }$ stands for the minimum fitness function value in contemporary population,
Gmax stands for the maximum fitness function value in contemporary population, $G_{\text {avg }}$ stands for the average value of all fitness functions in contemporary population, G' stands for the larger fitness function value of two chromosomes in the crossover operation, and $n_{1}, n_{2}, n_{3}, n_{4}, n_{5}$, and $n_{6}$ are all in $(0,1)$, and $n_{1}>n_{2}>n_{3}, n_{4}>n_{5}>n_{6}$.

For the dynamic scheduling in this study, the following settings are made.

\subsection{Chromosome coding}

In this study, there are 6 decision variables in the dynamic scheduling problem of supply inventory distribution, 5 with or without variables, and 1 nonnegative variables. Therefore, matrix coding [12] was used, and 1 solution was composed of 6 gene segments. A matrix was set up for the quantity and distribution way from the last to the next, and the quantity and distribution way from the last to the next were mutually corresponding.

\subsection{Initial population generation}

According to the objective function and conditional equation in the mathematical model, 30 initial solutions were randomly generated, and the unqualified solutions were modified to make all the initial solutions conform to the constraint conditions.

\subsection{Fitness value evaluation}

In this study, ranking function in the tool box of Matlab [13] was adopted as the evaluation fitness function of individuals, so as to avoid the problem of low selection probability caused by excessive penalty value of some individuals.

\subsection{Genetic manipulation}

In this study, the combination of roulette and elite selection was used as selection operator [15], and the crossover operator of matrix column crossing and mutation operator of matrix row crossing were used to correct the relationship between individual fragments. When iterations times of the algorithm reached 500 generations, the operation will be terminated regardless of whether the optimal solution was found.

\section{Simulation Example}

\subsection{Experimental environment}

In this study, Matlab simulation platform was used to write algorithm model, and the experiments were carried out on a laboratory server, which was equipped with Windows7 system, I7 processor, and 16G memory. 


\subsection{Basic parameters of examples}

Table 1: Basic parameters of examples

\begin{tabular}{|c|c|}
\hline Basic parameters & Value range \\
\hline $\begin{array}{l}\text { Average customer demand } \\
\text { (unit / month) }\end{array}$ & {$[12,24]$} \\
\hline $\begin{array}{l}\text { Standard deviation of customer } \\
\text { demand (unit / month) }\end{array}$ & {$[3,7]$} \\
\hline $\begin{array}{l}\text { Fixed operating cost of the } \\
\text { wholesale market (yuan / } \\
\text { month) }\end{array}$ & {$[450,600]$} \\
\hline $\begin{array}{l}\text { Inventory cost of the wholesale } \\
\text { market (yuan / unit/ month) }\end{array}$ & {$[31,33]$} \\
\hline $\begin{array}{l}\text { Inventory capacity of the } \\
\text { wholesale market (unit) }\end{array}$ & {$[110,170]$} \\
\hline $\begin{array}{l}\text { Order cost of the wholesale } \\
\text { market (yuan / unit) }\end{array}$ & {$[150,160]$} \\
\hline $\begin{array}{l}\text { Lead time for transportation } \\
\text { between the wholesale market } \\
\text { and the manufacturer (month / } \\
\text { times) }\end{array}$ & {$[1,5]$} \\
\hline $\begin{array}{l}\text { Transportation cost from the } \\
\text { supplier to the manufacturer } \\
\text { (yuan/unit) }\end{array}$ & {$[40,120]$} \\
\hline $\begin{array}{l}\text { Transportation cost from the } \\
\text { manufacturer to the wholesale } \\
\text { market (yuan / unit) }\end{array}$ & {$[15,45]$} \\
\hline $\begin{array}{l}\text { Transportation cost from the } \\
\text { wholesale market to customers } \\
\text { (yuan / unit) }\end{array}$ & {$[5,15]$} \\
\hline Supply of the supplier (unit) & {$[61,76]$} \\
\hline $\begin{array}{l}\text { Procurement cost of the } \\
\text { manufacturer at the supplier } \\
\text { (yuan / unit) }\end{array}$ & {$[350,500]$} \\
\hline $\begin{array}{l}\text { Fixed operating cost of the } \\
\text { manufacturer (yuan / month) }\end{array}$ & {$[6000,8000]$} \\
\hline $\begin{array}{l}\text { Inventory cost of the } \\
\text { manufacturer (yuan / unit / } \\
\text { month) }\end{array}$ & {$[250,350]$} \\
\hline Inventory service level & 0.9 \\
\hline $\begin{array}{l}\text { Under the condition of } \\
\text { standard normal distribution, } \\
\text { the inventory level meets the } \\
\text { required safety stock value }\end{array}$ & 1.6 \\
\hline $\begin{array}{l}\text { Maximum lead time of the } \\
\text { manufacturer (month / times) }\end{array}$ & {$[6,8]$} \\
\hline Production cost (yuan / unit) & {$[80,130]$} \\
\hline Productive capacity (unit) & {$[125,140]$} \\
\hline $\begin{array}{l}\text { Order cost of the manufacturer } \\
\text { (yuan / times) }\end{array}$ & {$[1200,1600]$} \\
\hline $\begin{array}{l}\text { Lead time for transportation } \\
\text { between the manufacturer and } \\
\text { the supplier (month / times) }\end{array}$ & {$[4,9]$} \\
\hline
\end{tabular}

In this study, five sets of examples of different scales were tested. The basic parameters of the five sets of examples are shown in Table 1, and the scale parameters are shown in Table 2 .

\subsection{Example scale and algorithm parameters setting}

Table 2: Example scale and algorithm parameters

\begin{tabular}{|c|c|c|c|c|}
\hline No. & $\begin{array}{l}\text { Example } \\
\text { scale }\end{array}$ & Algorithm & $\begin{array}{l}\text { Crossover } \\
\text { rate } \alpha\end{array}$ & $\begin{array}{l}\text { Mutation } \\
\text { rate } \beta\end{array}$ \\
\hline \multirow[t]{2}{*}{1} & \multirow[t]{2}{*}{$\begin{array}{l}5-4-6- \\
15\end{array}$} & $\begin{array}{l}\text { Genetic } \\
\text { algorithm }\end{array}$ & 0.8 & 0.1 \\
\hline & & $\begin{array}{l}\text { Adaptive } \\
\text { genetic } \\
\text { algorithm }\end{array}$ & $\begin{array}{l}\mathrm{In} \\
\text { formula } \\
(9): \\
\mathrm{n}_{1}=0.9 \\
\mathrm{n}_{2}=0.8 \\
\mathrm{n}_{3}=0.7\end{array}$ & $\begin{array}{l}\mathrm{In} \\
\text { formula } \\
(10): \\
\mathrm{n}_{4}=0.1, \\
\mathrm{n}_{5}=0.08 \\
\mathrm{n}_{6}=0.06\end{array}$ \\
\hline \multirow[t]{2}{*}{2} & \multirow[t]{2}{*}{$\begin{array}{l}\text { 5-4-6- } \\
20\end{array}$} & $\begin{array}{l}\text { Genetic } \\
\text { algorithm }\end{array}$ & 0.8 & 0.1 \\
\hline & & $\begin{array}{l}\text { Adaptive } \\
\text { genetic } \\
\text { algorithm }\end{array}$ & $\begin{array}{l}\text { In } \\
\text { formula } \\
(9): \\
n_{1}=0.9 \\
n_{2}=0.8 \\
n_{3}=0.7\end{array}$ & $\begin{array}{l}\text { In } \\
\text { formula } \\
(10): \\
n_{4}=0.1, \\
n_{5}=0.08, \\
n_{6}=0.06\end{array}$ \\
\hline \multirow[t]{2}{*}{3} & \multirow[t]{2}{*}{$\begin{array}{l}5-4-15- \\
20\end{array}$} & $\begin{array}{l}\text { Genetic } \\
\text { algorithm }\end{array}$ & 0.8 & 0.1 \\
\hline & & $\begin{array}{l}\text { Adaptive } \\
\text { genetic } \\
\text { algorithm }\end{array}$ & $\begin{array}{l}\text { In } \\
\text { formula } \\
(9): \\
n_{1}=0.9 \\
n_{2}=0.8 \\
n_{3}=0.7\end{array}$ & $\begin{array}{l}\text { In } \\
\text { formula } \\
(10): \\
n_{4}=0.1 \\
n_{5}=0.08 \\
n_{6}=0.06\end{array}$ \\
\hline \multirow[t]{2}{*}{4} & \multirow[t]{2}{*}{$\begin{array}{l}5-15- \\
15-20\end{array}$} & $\begin{array}{l}\text { Genetic } \\
\text { algorithm }\end{array}$ & 0.8 & 0.1 \\
\hline & & $\begin{array}{l}\text { Adaptive } \\
\text { genetic } \\
\text { algorithm }\end{array}$ & $\begin{array}{l}\text { In } \\
\text { formula } \\
(9): \\
n_{1}=0.9 \\
n_{2}=0.8 \\
n_{3}=0.7\end{array}$ & $\begin{array}{l}\text { In } \\
\text { formula } \\
(10): \\
n_{4}=0.1 \\
n_{5}=0.08 \\
n_{6}=0.06\end{array}$ \\
\hline \multirow[t]{2}{*}{5} & \multirow[t]{2}{*}{$\begin{array}{l}15-4-6- \\
20\end{array}$} & $\begin{array}{l}\text { Genetic } \\
\text { algorithm }\end{array}$ & 0.8 & 0.1 \\
\hline & & $\begin{array}{l}\text { Adaptive } \\
\text { genetic } \\
\text { algorithm }\end{array}$ & $\begin{array}{l}\text { In } \\
\text { formula } \\
(9): \\
n_{1}=0.9 \\
n_{2}=0.8 \\
n_{3}=0.7\end{array}$ & $\begin{array}{l}\text { In } \\
\text { formula } \\
(10): \\
n_{4}=0.1, \\
n_{5}=0.08, \\
n_{6}=0.06\end{array}$ \\
\hline
\end{tabular}

The scale of the five examples is shown in Table 2. In this study, genetic algorithm and adaptive genetic algorithm were adopted to calculate the objective function, so as to make comparison. The crossover rate and mutation rate of the two algorithms are shown in Table 2. 
Each set of example was tested for 30 times, the corresponding objective function value and running time were recorded, the optimal and the worst objective function values were selected, and the corresponding average objective function values and the average running time of the 30 sets of solutions were calculated.
Then, the best example was selected, and the maximum lead time of the manufacturer in this example was taken as benchmark 1 . The maximum lead time of the manufacturer was adjusted, and the adjustment multiple was 0.7-1.7. Each set of data was calculated 30 times, and the average value was calculated.

\subsection{Simulation results The comparison of two algorithms}

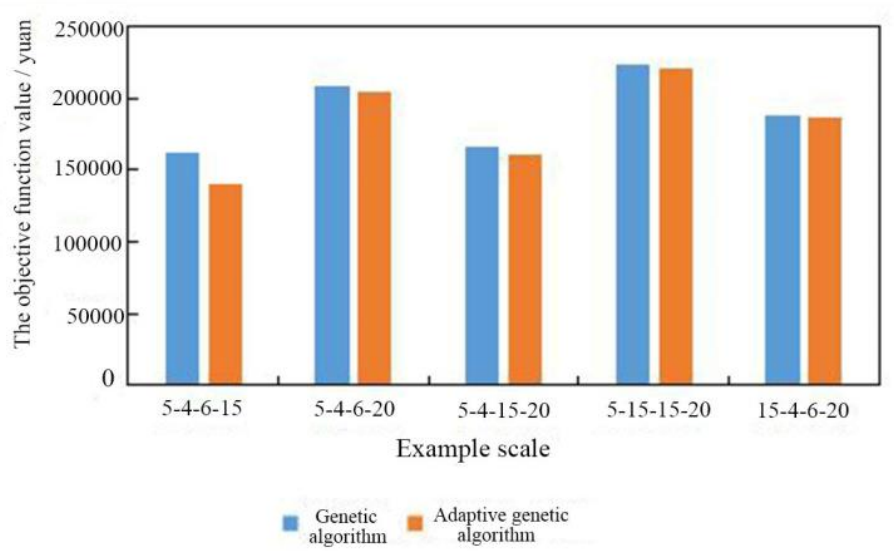

Figure 2: The corresponding objective function value of the optimal solution of the two algorithms with different example scales

The comparison of the corresponding objective function value of the optimal solution with five different example scales is shown in Figure 2.

We can find that the corresponding objective function value of the optimal solution of the adaptive genetic algorithm was lower than that of the genetic algorithm in any example, which meant that the total cost of the optimal solution of the dynamic scheduling problem obtained by the adaptive genetic algorithm was lower than that obtained by the genetic algorithm.

The corresponding objective function value of the optimal solution of the two algorithms was the lowest when the example scale was 5-4-6-15.

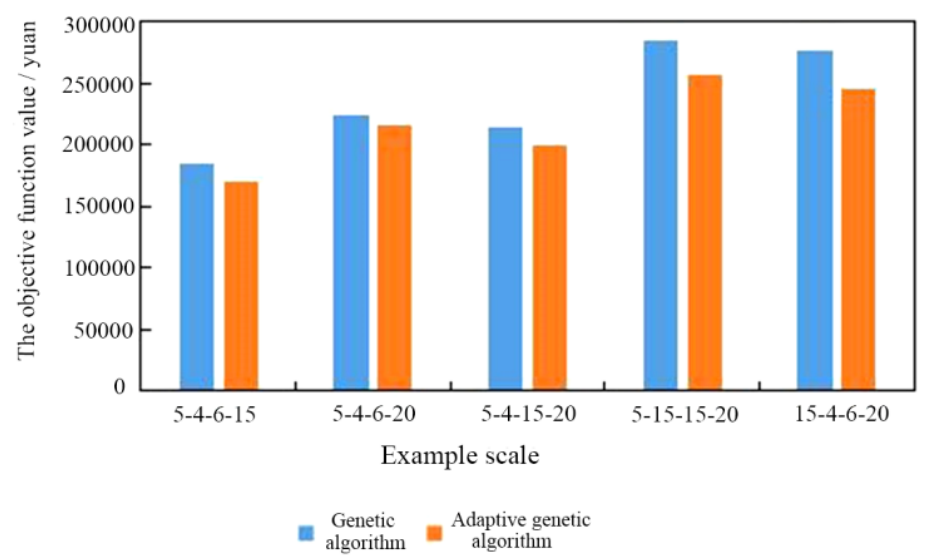

Figure 3: The corresponding objective function value of the worst solution with different example scales

The comparison of the corresponding objective function value of the worst solution with five different example scales is shown in Figure 3. We can find that the corresponding objective function value of the worst solution of the adaptive genetic algorithm was lower than that of the genetic algorithm in any example, which meant that the total cost of the worst solution of the dynamic scheduling problem obtained by the adaptive genetic algorithm was lower than that obtained by the genetic algorithm. The corresponding objective function value of the worst solution of the two algorithms was the lowest when the example scale was 5-4-6-15. 


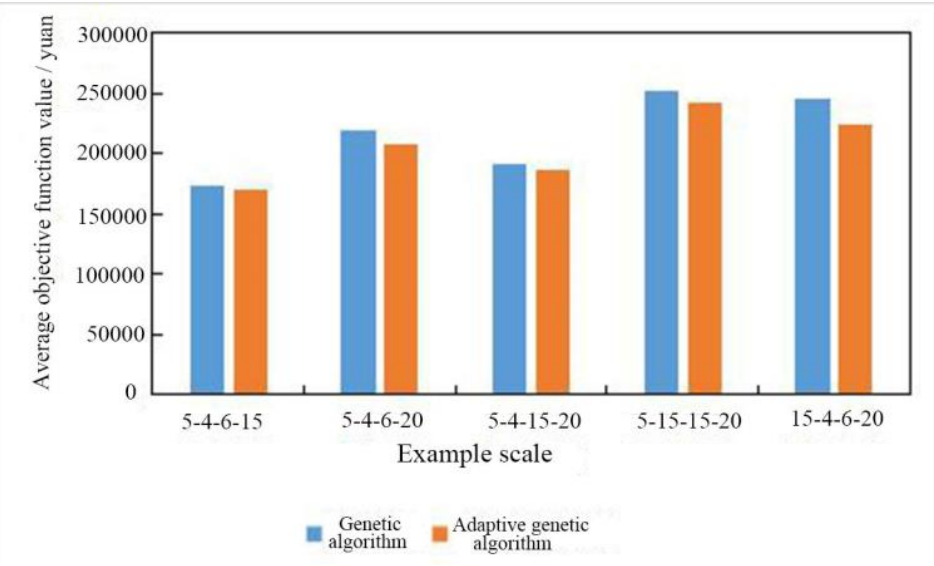

Figure 4: The corresponding average objective function value of 30 sets of solutions with different example scales

The comparison of the corresponding average objective function value of 30 sets of solutions with five example scales is shown in Figure 4.

We can find that the average objective function value of the adaptive genetic algorithm was lower than that of the genetic algorithm in any example, which meant that the average total cost of the dynamic scheduling problem obtained by the adaptive genetic algorithm was lower than that obtained by the genetic algorithm.

The average objective function value of the two algorithms was the lowest when the example scale was 5-4-6-15.

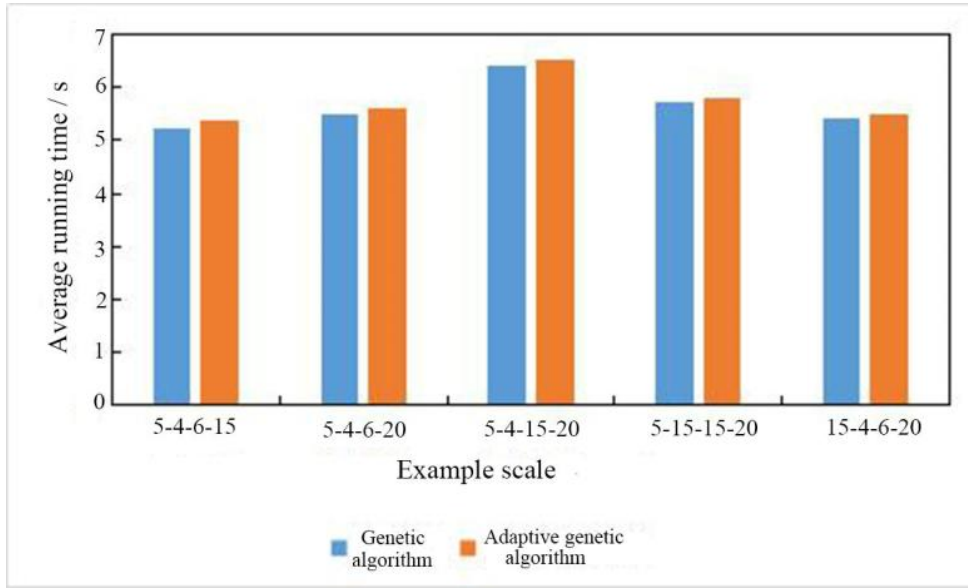

Figure 5: Average running time of 30 sets of solutions with different example scales

Average running time of 30 sets of solutions with five example scales is shown in Figure 5, we can find that the average running time of the adaptive genetic algorithm was slightly longer than that of the genetic algorithm in any example. The running time of two algorithms was shortest when the example scale was 5-4-6-15.

In conclusion, the optimal solution, the worst solution and the average objective function value obtained by the adaptive genetic algorithm were smaller than those obtained by the genetic algorithm, indicating that the adaptive genetic algorithm has a stronger capability of searching optimal solution than the genetic algorithm. However, the solving running time of the adaptive genetic algorithm was slightly longer, and the difference was not significant. After comprehensive consideration, the adaptive genetic algorithm was more excellent.

\section{Cost variation law of dynamic scheduling of inventory distribution}

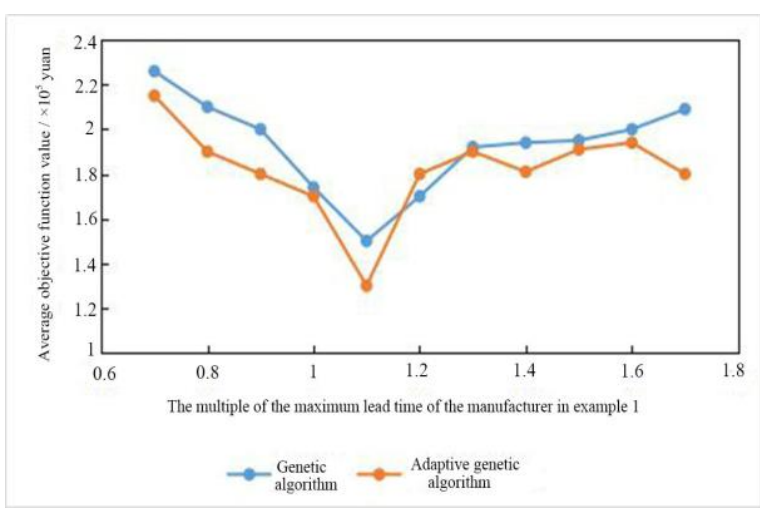

Figure 6: The cost of dynamic scheduling of inventory distribution under the maximum lead time of different manufacturers 
From the above, it can be seen that the result of the example 1 was the best, and the maximum lead time of the manufacturer was adjusted based on the example 1, and the final result is shown in Figure 6. It can be seen from the Figure 6 that the multiple of lead time was in the range of 0.7-1.1, and the average objective function value of the dynamic scheduling, i.e., the cost, decreased as the lead time increased. When the maximum lead time is reduced, the order becomes urgent, and the manufacturer will increase the cost of purchasing, transportation and production to complete the order, which ultimately leads to an increase in the total cost.

The multiple of the lead time was in the range of 1.1-1.7, the cost of dynamic scheduling increased as the lead time increased. The reason is that the manufacturer will produce more and store them and meet the customer requirements in time when the order is not urgent, but a large amount of storage will increase the inventory cost, which will eventually lead to an increase in the total cost. When the multiple was 1.1, the total cost of dynamic scheduling was the smallest.

Therefore, operators of dynamic scheduling of inventory distribution need to determine the best maximum lead time to reduce the operating cost of the entire dynamic scheduling.

\section{Conclusion}

In this study, the adaptive genetic algorithm was used to calculate the optimal solution of dynamic dispatching of supply inventory in uncertain environment. The effectiveness of genetic algorithm and adaptive genetic algorithm was verified by numerical simulation experiments on Matlab.

Finally, the following conclusions are drawn:

(1) The optimal solution, the worst solution and the average objective function value obtained by the adaptive genetic algorithm were smaller than those obtained by the genetic algorithm, indicating that the adaptive genetic algorithm has a stronger capability of searching optimal solution than the genetic algorithm. However, the solving running time of the adaptive genetic algorithm was slightly longer, and the difference was not significant. After comprehensive consideration, the adaptive genetic algorithm was more suitable for the dynamic scheduling problem of this study.

(2) The total cost of dynamic scheduling was related to the maximum lead time of the manufacturer. It tended to decrease first and then increase with the increase of the maximum lead time. Determining the best maximum lead time is conducive to reduce the total cost of dynamic scheduling.

\section{References}

[1] Li W, Zhou J, Lin Z, Zhang X. (2017). HadoopBased Dynamic Load Balance Scheduling Algorithm of Logistics Inventory. International Conference on Computational Intelligence and Security, IEEE, Wuxi, China, pp. 5-8.

[2] Cheng B, Ming LI, Management SO. (2015). Ant Colony Optimization for Joint Scheduling of Production, Inventory and Distribution. Journal of Mechanical Engineering, 51(12), pp. 202-212.

[3] Liu B, Fan Y, Liu Y. (2015). A fast estimation of distribution algorithm for dynamic fuzzy flexible job-shop scheduling problem. Computers \& Industrial Engineering, pp. 193201.

[4] Kar MB, Bera S, Das D, Kar S. (2015). A production-inventory model with permissible delay incorporating learning effect in random planning horizon using genetic algorithm. Journal of Industrial Engineering International, 11(4), pp. 555-574.

[5] Cannella S, Framinan JM, Bruccoleri M, BarbosaPóvoa AP, Relvas S. (2015). The effect of Inventory Record Inaccuracy in Information Exchange Supply Chains. European Journal of Operational Research, 243(1), pp. 120-129.

[6] Mohtashami A. (2015). A novel dynamic genetic algorithm-based method for vehicle scheduling in cross docking systems with frequent unloading operation. Computers \& Industrial Engineering, 90(C), pp. 221-240.

[7] Wang D, Luo H. (2016). Simultaneous Lot-Sizing and Scheduling for Single-Stage Multi-product Production-Distribution System with Due Date Considerations to Minimize Total Logistics Cost. International Conference on Intelligent HumanMachine Systems and Cybernetics, IEEE, Hangzhou, China.

[8] Jauhar S K, Pant M. (2015). Genetic Algorithms, a Nature-Inspired Tool: Review of Applications in Supply Chain Management. Advances in Intelligent Systems \& Computing, pp. 71-86.

[9] İnkaya T, Akansel M. (2017). Coordinated scheduling of the transfer lots in an assemblytype supply chain: a genetic algorithm approach. Journal of Intelligent Manufacturing 28(4), pp. 1-11.

[10] Afzalirad M, Shafipour M. (2018). Design of an efficient genetic algorithm for resourceconstrained unrelated parallel machine scheduling problem with machine eligibility restrictions. Journal of Intelligent Manufacturing, pp. 1-15.

[11] Sweeney E. (2015). Decision support system for vendor managed inventory supply chain: a case study. International Journal of Production Research, 53(16), pp. 4789-4818. 
[12] Roychowdhury S, Allen TT, Allen NB. (2017). A Genetic Algorithm with an Earliest Due Date Encoding for Scheduling Automotive Stamping Operations. Computers \& Industrial Engineering, pp. 201-209.

[13] Zheng Z, Guo J, Gill E. (2017). Swarm satellite mission scheduling \& planning using Hybrid Dynamic Mutation Genetic Algorithm. Acta Astronautica, pp. 243-253.
[14] Hussein QM, Hasoon AN. (2017). Dynamic process scheduling using genetic algorithm. New Trends in Information \& Communications Technology Applications, IEEE, Baghdad, Iraq, pp. 111-115.

[15] Roy T, Das A, Ni Z. (2017). Optimization in load scheduling of a residential community using dynamic pricing. Power \& Energy Society Innovative Smart Grid Technologies Conference, IEEE, Washington, DC, USA, pp. 1-5. 